\title{
A Study of the Fatty Acid Profile in the Muscle of Monopterus chuchia
}

\author{
MITA DUTTA ${ }^{1}$ and PINAK DUTTA ${ }^{2 *}$ \\ 'Department of Chemistry, Sreegopal Banerjee College, Bagati, Magra, Hooghly - 712 148, India. \\ ${ }^{2}$ Department of Chemistry, Bejoy Narayan Mahavidyalaya, Itachuna, Hooghly - 712 147, India. \\ ${ }^{*}$ Corresponding author E-mail: pimidu@yahoo.com \\ http://dx.doi.org/10.13005/ojc/290428
}

(Received: October 10, 2013; Accepted: November 25, 2013)

\begin{abstract}
The nutritional capacity of the fish Monopterus chuchia in terms of its fatty acid content was investigated to get an insight of their fatty acid composition in their most consumed part i.e. their muscle tissue. Our investigation shows the presence of SFA's like caproic acid, caprylic acid, palmitic acid, pentadecanoic acid, heptadecanoic acid, behenic acid, MUFA's like myristoleic acid, palmitoleic acid, oleic acid and nutritionally important PUFA's like Eicosapentaenoic acid, docosahexaenoic acid in major amount. Erucic acid, which is reported to be an anti-nutritional factor, is present in extremely low concentration. Thus the fish which is generally consumed by very few can be farmed as a cheap nutritional source for the masses.
\end{abstract}

Key words: Monopterus chuchia, fatty acid profile, PUFA, MUFA, SFA, Palmitoleic acid.

\section{INTRODUCTION}

It is a well known fact that besides being a beneficial protein source, fishes are a source of polyunsaturated fatty acids (PUFA). Fatty acids are essential nutrients in humans ${ }^{1-5}$ and other animal diet. Compared to chicken and beef the content of $n-3$ PUFA is higher in fish. These n-3 PUFA's have cardioprotective ${ }^{6}$, anti atherosclerotic ${ }^{7}$, antithrombotic ${ }^{8}$ properties. These poly unsaturated fatty acids can also prevent arrhythmias, endothelial dysfunction, high blood pressure, sudden strokes and heart attack ${ }^{9-11}$.

According to an article in Circulation ${ }^{12}$ as fatty acids in fish block dangerous heart rhythms, eating oily fish at least twice a week may be helpful in preventing sudden death from heart attack. Excessive sodium and calcium currents in the heart which can cause dangerous unpredictable changes of individual heart cells show that fatty acids are capable of blocking such currents. It is also seen that a diet rich in oily fish is capable of reducing the effects of arthiritis ${ }^{14}$ by producing an antiinflammatory fat. According to French researchers people who eat fish at least once a week are less prone to dementia ${ }^{13}$. Some researchers of Edinburg and Stirling Universities even suggest that fish could be of help in dealing with childhood autism. Thus the importance of consumption of unsaturated fatty 
acids, the best source of which is fish oil cannot be ignored. So effort to detect and preserve both fresh water and salt water fish rich in unsaturated fatty acids is evident throughout the world ${ }^{15-18}$.

Monopterus chuchia is a fish very common in West Bengal ${ }^{19}$ inhabiting fresh and brackish waters. It is found at an altitudinal range $(76-1350)$ $\mathrm{m}$. This fish belongs to the family Synbranchiformes. They have a burrowing habit ${ }^{20}$. It can thrive in various adverse conditions such as high temperature, shallow water and low oxygen levels. In West Bengal and Bangladesh the fish is consumed by tribal people and people of few other castes. It is prepared as soup, fry or boiled with piper nigrum and is considered a curative for anaemia and piles ${ }^{21}$. Though the consumption of the fish is limited to tribal people, it is commercially very important for its high export demand. From the Noakhali area in Bangladesh alone an average of $28,000 \mathrm{~kg}$ of fish per month is collected for export ${ }^{22}$. Recently however the abundance of this species is declining due to a variety of reasons like habitat destruction, aquatic pollution, indiscriminate use of pesticide and heavy fishing pressure. The species is gradually becoming a vulnerable one and a management programme to conserve the species is gradually becoming unavoidable. If species conservation and commercial aspect does not provide reason enough for undertaking a management programme then nutritional capacity of the species if found considerable should certainly provide good reason and strong motivation. However, only a few works so far has been reported to determine the nutritional capacity of the fish species Monopterus ${ }^{23}$.

We, in our laboratory have taken up the task of determining the nutritional capacity of Monopterus chuchia in terms of its fatty acid content and hereby wish to report our interesting initial finding.

\section{MATERIAL AND METHODS}

Six fish samples were caught from the same pond in Panduah, W.B., India in January 2012. Average weight of the fish is around (500 \pm 7.25) gms. The fishes killed by hitting on their heads were brought to the laboratory and stored at $-30^{\circ} \mathrm{C}$ in a freezer until they were used ${ }^{24}$. After measuring total length and weight of the fishes, their proximate compositions were analyzed according the procedure laid down in $\mathrm{AOAC}^{25}$. The edible portions (the muscle tissues of the body) were separated from the head, skin, bone and viscera. The body muscles were removed from the bones and cut into small pieces. They were then blended in a sterilized mixer grinder for 30 seconds. $5 \mathrm{gms}$ of the minced pieces were used for extraction of total lipids with a chloroform-methanol mixture in accordance to the method of Folch et. al. ${ }^{26}$ After extraction the crude lipid was purified, dried and weighed by using methods of Folch et.al. ${ }^{26}$. The extracted lipids were esterified with $\mathrm{BF}_{3}-\mathrm{MeOH}$ and recovered in heptanes ${ }^{25}$. The purified fatty acid methyl esters (FAME) mixture obtained was analyzed using a Shimadzu Gas Chromatograph (Model: GC-2010, Shimadzu, Japan) with a Flame ionization detector (FID) on a split injector. A SP-2560 capillary column (100 m long x $0.25 \mathrm{~mm}$ i.d) was used for FAME analysis. Oxygen free nitrogen was used as a carrier gas at a flow rate of $33.9 \mathrm{ml} /$ minute. The initial oven temperature was $140{ }^{\circ} \mathrm{C}$ for 5 minutes which was slowly raised to $240{ }^{\circ} \mathrm{C}$ at a rate of $4{ }^{\circ} \mathrm{C} / \mathrm{min}$. and finally held at $240{ }^{\circ} \mathrm{C}$ for 20 minutes. The injector and detector temperature were finally set at $260^{\circ} \mathrm{C}$. Volume injected $1 \mu \mathrm{l}$; split ratio, 1:30. Peaks obtained were identified by comparison of their retention times with that of standard fatty acid methyl esters. The percentage compositions of the samples under investigation were computed from the G.C peak areas. The results obtained were placed in Table 1.

\section{RESULTS AND DISCUSSION}

The proximate composition (\%) analysis of mud eel (Monopterus chuchia) reveals its protein content to be [19.72 \pm 0.20$]$ and lipid content to be [3.47 \pm 0.05$]$. The moisture and ash content of the fish was $[74.81 \pm 0.50]$ and $[1.89 \pm 0.07]$ respectively.

Table 1 shows that among the saturated fatty acids (SFA) detected in this fish species, the ones that need mention are Caproic acid (C6:0), Caprylic acid (C8:0), Myristic acid (C14:0), Pentadecanoic acid (C15:0), Palmitic acid (C16:0), Heptadecanoic acid (C17:0), Stearic acid (C18:0), Behenic acid (C22:0). Among them Heptadecanoic acid $(C 17: 0)$ is present in highest amount. The important mono unsaturated fatty acids (MUFA) detected include Myristoleic acid (C14:1), cis10-Pentadecanoic acid (C15:1), Palmitoleic acid 
(C16:1), cis-10-Heptadecanoic acid (C17:1), Oleic acid (C18:1), Erucic acid (C22:1). Among these monounsaturated fatty acids, palmitoleic acid $(16: 1)$ is present in highest amount. Among the polyunsaturated $n-3$ and $n-6$ fatty acids (PUFA) Linoleic acid (C18:2 n6) , cis-11,14-Eicosadienoic

\section{Table 1: Fatty acid profile in muscle tissues of Monopterus chuchia}

\begin{tabular}{|c|c|}
\hline Fame & M. chuchia \\
\hline Caproic acid (C6:0) & $1.50 \pm 0.03464$ \\
\hline Caprylic acid (C8:0) & $3.06 \pm 0.07537$ \\
\hline Myristic acid (C14:0) & $0.84 \pm 0.04472$ \\
\hline Pentadecanoic acid (C15:0) & $8.15 \pm 0.07183$ \\
\hline Palmitic acid (C16:0) & $2.23 \pm 0.05621$ \\
\hline Heptadecanoic acid (C17:0) & $35.29 \pm 0.0498$ \\
\hline Stearic acid (C18:0) & $1.04 \pm 0.0502$ \\
\hline Behenic acid (C22:0) & $1.45 \pm 0.03286$ \\
\hline$\Sigma$ SFA & $53.56 \pm 0.13115$ \\
\hline Myristoleic acid (C14:1) & $1.97 \pm 0.0498$ \\
\hline Cis-10-Pentadecenoic acid & \\
\hline$(\mathrm{C} 15: 1)$ & $4.54 \pm 0.0228$ \\
\hline Palmitoleic acid (C16:1) & $11.16 \pm 0.07183$ \\
\hline Cis-10-Heptadecenoic acid & \\
\hline$(\mathrm{C} 17: 1)$ & $7.31 \pm 0.0405$ \\
\hline Oleic acid (18:1) & $0.43 \pm 0.02608$ \\
\hline Erucic acid (C22:1) & $0.40 \pm 0.03033$ \\
\hline$\Sigma$ MUFA & $25.81 \pm 0.10621$ \\
\hline Linoleic acid (C18:2 n6) & $2.77 \pm 0.02828$ \\
\hline$\gamma$-Linolenic acid (C18:3 n6) & $0.29 \pm 0.03406$ \\
\hline Cis-11,14-Eicosadienoic acid & \\
\hline (C20:2 n6) & $0.90 \pm 0.0494$ \\
\hline Cis-8,11,14-Eicosatrienoic acid & \\
\hline (C20:3 n6) & $0.78 \pm 0.0555$ \\
\hline Arachidonic acid (C20:4 n6) & $1.07 \pm 0.05292$ \\
\hline Cis-13,16-Docosadienoic acid & \\
\hline (C22:2 n6) & $0.66 \pm 0.04243$ \\
\hline$\sum \mathrm{n}-6$ PUFA & $6.47 \pm 0.12474$ \\
\hline Linolenic acid (C18:3 n3) & $2.77 \pm 0.06812$ \\
\hline Cis-11-14-17-Eicosatrienoic & \\
\hline acid (C20:3 n3) & $1.30 \pm 0.04243$ \\
\hline $\begin{array}{l}\text { Cis-5-8-11-14-17-Eicosape- } \\
\text { ntaenoic acid (C20:5 n3) }\end{array}$ & $4.94 \pm 0.0494$ \\
\hline $\begin{array}{l}\text { Cis-4-7-10-13-16-19-Doco- } \\
\text { sahexaenoic acid (C22:6 n3) }\end{array}$ & $0.58 \pm 0.03578$ \\
\hline$\Sigma n-3$ PUFA & $9.59 \pm 0.09274$ \\
\hline$n-3 / n-6$ & $1.48256 \pm 0.02381$ \\
\hline
\end{tabular}

acid (C20:2 n6), cis-8,11,14-Eicosatrienoic acid (C20:3 n6), Arachidonic acid(C20:4n6), cis11,14,17-Eicosatrienoic acid (C20:3 n3), cis5,8,11,14,17-Eicosapentanoic acid(C20:5 n3) and cis-4,7,10,13,16,19-Docosohexanoic acid (C22:6n3) are worth mentioning.

A common constituents of glycerides of human adipose tissue, found in high concentration in liver, is palmitoleic acid. It is biosynthesized from palmitic acid, which is also detected in this fish species. Palmitoleic acid is present in considerable amount in Monopterus chuchia. It is a beneficial fatty acid which increases insulin sensitivity by suppressing inflammation and inhibits the destruction of pancreatic beta-cells which are known to secrete insulin $^{27}$. Linoleic acid, which is a precursor of $n-6$ PUFA is also present in this fish. The presence of Arachidonic acid (20:4, n-6), EPA (20:5 n-3) and DHA $(22: 6 n-3)$ in this fish species suggests, that this fish has a tendency to conserve these unsaturated fatty acids, a metabolic priority for their conservation ${ }^{28}$. The presence of arachidonic acid is in accordance with the finding of Ackman ${ }^{29,30}$ that fresh water fishes have good level of arachidonic acid.

Erucic acid which is known to be an anti-nutritional factor which induces an increased incidence of myocardial lipidosis in animal ${ }^{31}$ is also present in this fish though in very small amount.

Another important aspect which must be noted is the $n-3: n-6$ ratio of the unsaturated fatty acids of this fish which is an useful indicator for comparing relative nutritional values of fish oil. A ratio within 1.1 to 1.5 is considered healthy for human diet $^{32}$. The $n-3: n-6$ ratio of this fish is around 1.48 which suggests that this fish can be a good nutritious diet.

According to the recommendation of British Nutrition Foundation ${ }^{33}$, a persons balanced and healthy diet must contain 0.2 gm of EPA + DHA daily or at least $1.5 \mathrm{gms}$ of EPA + DHA on a weekly basis. Based on the above finding and recommendation, one can easily conclude that Monopterus chuchia is a potentially nutritious food with health benefits for the population of West Bengal, India. 


\section{CONCLUSION}

The fatty acid composition of this fish (Monopterus chuchia) which is gradually becoming a vulnerable one due to indiscriminate fishing, suggests that the fish has considerable nutritional capacity from the finding carried out in our laboratory. The great commercial importance and need of species conservation makes the need for undertaking a management programme for this species unavoidable. Meticulous farming by incorporating desired fatty acids like linoleic acid, linolenic acid, EPA, DHA into their feed will certainly help maintaining a healthy population and improve the nutritional capacity of the fish.

\section{ACKNOWLEDGEMENTS}

P. D thanks the UGC, New Delhi for the financial assistance extended through a minor research project (Project No. F.PSW-006/09-10). P.D and M.D also thanks Prof. S. Laskar and the Department of Chemistry, Burdwan University for extending all sorts of intellectual and infrastructural support required for completing this project.

\section{REFERENCES}

1. Simopoulos, A. Am. J. Clin. Nutr., 54: 438-463 (1952).

2. Pepping, J. Am. J. Health Syst. Pharm., 56: 719-720 (1999).

3. Jensen, C.L. et al. Am. J. Clin. Nutr., 71(suppl): 292S-299S (2000).

4. Makrides; Maria; Gibson; Robert, A. Am. J. Clin. Nutr., 71(suppl), 307S-311S (2000).

5. Montano, N.; Gavina, G.; Gavino, V.C. Food Chem., 75: 611-614 (2001).

6. Sanderson, P.; Finnegan, Y.E.; Williams, C.M.; Calder, P.C.; Burdge, G.C.; Wootton, S.A.; Griffin, B.A.; Millward, D.J.; Pegge, N.C.; Bemelmans, W.J.E. Br. J. Nutr., 88: 573-579 (2002).

7. Givens, D.I.; Kliem, K.E.; Gibbs, R.A. Meat Sc., 74: 209-218 (2006).

8. Calder, P.C., Nutr. Research, 24: 761-772 (2004).

9. Laugharne, J.D.E. et al. Lipids, 31(suppl): S163-S165 (1996).

10. Connor, W.E. Am. J. Clin. Nutr., 71(suppl): 171S-175S (2000).

11. Harris, W.S. Int. Congr. Ser., 1262: 380-383 (2004).

12. Leaf, A.; Kang, J.X.; Xiao, Y.; Billman, G. Circulation, 107: 2646-2652 (2003).

13. Arita, M.; Bianchini, F.; Aliberti, J.; Sher, A.; Chiang, N.; Hong, S.; Yang, R.; Petasis, N.A.; Serhan, C.N. J. Expt. Med., 201: 713-722 (2005).

14. Emma, W. BBC News Retrieved 2009-07-27 (2009).

15. Gulzar, S.; Zuber, M. Int. J. Agri. \& Biol., 2: 342-343 (2000).
16. Mukhopadhyay, T.; Nandi, S.; Ghosh, S. J. Oleo Sci., 53: 323-328 (2004).

17. Sharma, S.; Kumar, V.; Sinha, A.K.; Ranjan, J.; Kithsiri, H.M.P.; Venkateshwarlu, G., Fish Physiol. Biochem., 36: 411-417 (2010).

18. Memon, N.N.; Talpur, F.N.; Bhanger, M.I.; Balouch, A., Food Chem., 126: 405-410 (2011).

19. Jhingran $\vee \mathrm{G}$ and Talwar P K (1991), Inland Fishes of India and AdjacentCountries 2, Oxford and IBH Publishing Co. Pvt. Ltd. New Delhi. pp. 579-591 (1991).

20. Nasar S. S. T. "Backyard Eel Culture", International Institute of Rural Reconstruction, Silag, Cavity, Philippines, p. 88 (1997).

21. Saikia, K.; Ahmed, R. The Clarion, 1: 81-86 (2012).

22. Hassan, M.; Sarker, B.S.; Nazrul, K.M.S.; Rahman, M.; Mamun, A-A. Internation Journal of Life Sciences Biotechnology and Pharma Research 1: 226-233 (2012).

23. Zhou, Q-B.; Wu, H-D.; Zhu, C-S.; Yan X-H. Fish Physiol Biochem., 37: 433-445 (2011).

24. Gill, H.S.; Weatherley, A.H. J. Fish Biol., 25: 491-500 (1984).

25. AOAC. Official methods of analysis of AOAC International, vol. 1, $16^{\text {th }}$ edn. AOAC International, Arlington (1995).

26. Folch, J.; Lees, M.; Sloane-Stanley, G.H. J. Biol. Chem., 226: 497-509 (1957).

27. Yang Z-H.; Miyahara, H.; Hatanaka, A. Lipids in Health and Disease 10: 120 (2011).

28. Rainuzzo, J.R.; Reitan, K.I.; Jorgensen, L.; Olsen, Y. Biochem. Physiol., 107A: 699-710 (1994). 
29. Ackman, R.G.; Mcleod, C.; Rakshit, S.; Misra, K.K. J. Food Lipids, 9: 127-145 (2002).

30. Ackman, R.G. Eur. J. Lipid Technol., 104: 253-254 (2002).

31. Food Standards Australia New Zealand. Food Standards Australia New Zealand, Canberra (2003).
32. Zuraini, A.; Somchit, M.N.; Solihah, M.H.; Goh, Y.M.; Arifah, A.K.; Zakaria, M.S. et al. Fish Food Chem., 97: 674-678 (2006).

33. British Nutrition Foundation. Report of the British nutritional foundation. London: Chapman and Hall., 156 (1992). 